\title{
Comparison of static and dynamic methods based on knee kinematics to determine optimal saddle height in cycling
}

\author{
Geoffrey Millour*, Sebastien Duc, Frederic Puel, William Bertucci
}

Laboratory of Performance, Health, Metrology, and Society, University of Reims Champagne-Ardenne, Reims, France.

\begin{abstract}
Purpose: Bike-fitting methods based on knee kinematics have been proposed to determine optimal saddle height. The Holmes method recommends that knee angle be between $25^{\circ}$ and $35^{\circ}$ when the pedal is at bottom dead centre in static. Other authors advocate knee angle of $30-40^{\circ}$ during maximum knee extension while pedalling. Although knee angle would be $5-10^{\circ}$ greater at bottom dead centre during pedalling, no study has reported reference values in this condition. The purpose of this study was to compare these three methodologies on knee, hip, and ankle angles and to develop new dynamic reference range at bottom dead centre. Methods: Twenty-six cyclists volunteered for this experiment and performed a pedalling test on their personal road or mountain bike. Knee, hip, and ankle angles were assessed by two-dimensional video analysis. Results: Dynamic knee angle was $8^{\circ}$ significantly greater than static knee angle when the pedal was at bottom dead centre. Moreover, dynamic knee angle with the pedal at bottom dead centre was $3^{\circ}$ significantly greater than dynamic knee angle during maximum knee extension. The chosen methodology also significantly impacted hip and ankle angles under most conditions. Conclusions: The results allow us to suggest a new range of $33-43^{\circ}$ when the pedal is at bottom dead centre during pedalling. Thus, this study defines clearly the different ranges to determine optimal saddle height in cycling according to the condition of measurement. These findings are important for researchers and bike-fitting professionals to avoid saddle height adjustment errors that can affect cyclists' health and performance.
\end{abstract}

Key words: performance, comfort, joint biomechanics, injury prevention

\section{Introduction}

Cycling is considered as a popular recreational and sport activity and is also recommended for health and rehabilitation programs [17]. For a beneficial practice, the optimisation of the cyclist's position is essential. Saddle height, corresponding to the measure between the centre of the bottom bracket to the top of the saddle measured in alignment with the seat tube, is considered as one of the most important variables of the cyclist's position [11]. Proper saddle height has been suggested to prevent overuse injuries improving pedalling biomechanics [4], [16]. That implies optimisation of muscular activity [28] and joint kinematics [23], and thus a reduction of joint mechanical work contribu- tion [3]. Moreover, saddle height impacts cycling performance and particularly physiological parameters [9]-[14] and crank power output production [20]. Finally, a proper saddle height is essential for the bike handling [12], the comfort [19]-[28] and the perception of fatigue and pain while cycling [25]. However, there is some controversy between the proposed methods to adjust the saddle height [4].

On the one hand, bike fitting methods based on inseam length (IL, distance from the ischium to the ground, Fig. 1) have been purposed to determine optimal saddle height. The Genzling method suggests multiplying the IL by $88.5 \%$ [13] and the Hamley method by $109 \%$ minus crank arm length [14] to optimise power output production. Recently, Millour, Duc, Puel, and Bertucci [19] advised using the Genzling

\footnotetext{
* Corresponding author: Geoffrey Millour, Laboratory of performance, health, metrology, and society (EA 7507), UFR STAPS, University of Reims Champagne-Ardenne, Reims, France. Phone: +33 (6) 3534 36 52, e-mail: geoffrey.millour@univ-reims.fr

Received: July 29th 2019

Accepted for publication: October 10th 2019
} 
method for long IL $(>0.88 \mathrm{~m})$, the Hamley method for short IL $(<0.80 \mathrm{~m})$ and one or the other for people with an inseam length between $0.80 \mathrm{~m}$ and $0.88 \mathrm{~m}$ in order to optimise the joint angles and the comfort. On the other hand, kinematic methods based on knee angle (KA: angle between the thigh and the leg; $0^{\circ}$ corresponds to full knee extension) have been developed for assessing the optimal saddle height to prevent injuries and to increase performance. They are considered accurate because they take the differences in thigh, shank and foot length between individuals into account [6]. Among them, the Holmes method recommends to use a saddle height that involves a $\mathrm{KA}$ of $25-35^{\circ}$ when the pedal is at bottom dead centre (BDC), i.e., the lowest point of the crank cycle, without pedalling (static BDC) for injury prevention [16]. More recently, the authors recommended a knee angle of $25^{\circ}$ while static BDC for both submaximal cycling economy and anaerobic power production [20], [21]. Optimisation of saddle height based on KA while pedalling (i.e., dynamic condition), which can be evaluated by two-dimensional video analysis [9], [11], [23], is more and more frequently used to respect usual practice conditions [10], [11]. KA measured at BDC in dynamic condition (Dynamic BDC) would be $5^{\circ}$ to $10^{\circ}$ higher than during static condition due to the lateral pelvic tilt [8], or the increase of ankle angle (angle between the leg and the foot) [6], [15],[22] and the decrease of hip angle (angle between the thigh and the horizontal) [6]. However, no specific angle range has been suggested in this condition of measurement. Based on the previous studies which observed differences between Static BDC and Dynamic BDC, the Ferrer-Roca method suggests using a saddle height that induces a $\mathrm{KA}$ in the range of $30-40^{\circ}$ while pedalling at maximum knee extension (Dynamic MKE) which occurs when the crank arm is parallel to the seat tube [10]. It is relevant to note that the lower limb is fully extended in this condition, which is not the case during Dynamic BDC due to the seat tube angle of the road bikes between 72 and $74^{\circ}[23]$ that could impact lower limb joint angles. Therefore, the lack of recommendations for optimal KA during pedalling [15]-[22] could lead to misinterpretations for cyclists, researchers and bike-fitting professionals. Indeed, the difference of KA between Dynamic BDC and the ranges of $25-35^{\circ}$ while Static BDC and $30-40^{\circ}$ during Dynamic MKE is unclear and needs to be examined in order to avoid saddle height adjustment errors related to the methodology used. Given the impact of saddle height on performance, health, comfort, and bike handling, it seems therefore essential to compare the various methods and to de- velop independent dynamic reference values for dynamic BDC [15].

The purpose of this study was to compare lower limb joint angles with optimal saddle height computed with the Millour method [17] during 1) Static BDC, 2) Dynamic MKE while submaximal pedalling, and 3) Dynamic BDC while submaximal pedalling. The hypothesis was that the measurement condition for similar saddle height implies different KA due to a modification of lower limb kinematics in its entirety and that Dynamic BDC needs an independent optimal range of knee angle for saddle height adjustment.

\section{Materials and methods}

\section{Subjects}

Twenty-six male cyclists, aged 9 to 53 years, were recruited (Mean \pm SD: $27 \pm 15$ years old, $1.70 \pm 0.18 \mathrm{~m}$, $61.8 \pm 20.5 \mathrm{~kg})$. Their training status was from recreational to competitive road cyclists [26]. They had not reported any injuries or asymmetry between the two legs that can impact the joint kinematics during pedalling. After having been informed of the risks and benefits of the study, the cyclists, or the parents of the minors, provided an informed consent. The study was approved by the University of Reims ChampagneArdenne's biomedical research ethics committee in accordance with the Declaration of Helsinki. During the tests, participants used their personal road bike or mountain bike (according to their specialities) with a seat tube angle between 72 and $75^{\circ}$, their cycling shoes and their clipless pedals in order to reproduce usual practice conditions. Saddle height was computed with the Hamley method (equal to $109 \%$ of IL minus crank arm length) for children with IL lower than $0.80 \mathrm{~m}$ and with the Genzling method (equal to $85 \%$ of IL) for adults with IL greater than $0.80 \mathrm{~m}$ [19]. Prior to the experiment, the inseam length (IL) of each participant was measured with a ML Size ${ }^{\circledR}$ device (Morphologics, Saint-Malo, France, Fig. 1), that provides measurements to $1 \mathrm{~mm}$ through mobile sensors (AS5304, ams AG, Premstaetten, Austria) connected by Bluetooth transmission to a tablet computer. IL of children (IL $<0.80 \mathrm{~m}$ ) and adults (IL $>0.80 \mathrm{~m}$ ) were $0.708 \pm 0.034 \mathrm{~m}$ and $0.884 \pm 0.041 \mathrm{~m}$, respectively, and their bicycle crank arm lengths were 0.168 $\pm 0.007 \mathrm{~m}$ and $0.173 \pm 0.002 \mathrm{~m}$, respectively. The saddle fore-aft position, which corresponds to the horizontal distance between the front tip of the saddle 
and the centre of the bottom bracket, was adjusted using the Silberman method [27] by aligning the inferior pole of the patella directly over the pedal axle. The longitudinal cleat position was standardised by aligning the centre of the cleat with the first metatarsal head using a ML Cleat ${ }^{\circledR}$ tool (Morphologics, SaintMalo, France) for controlling the impact of this factor on joint angles [7].

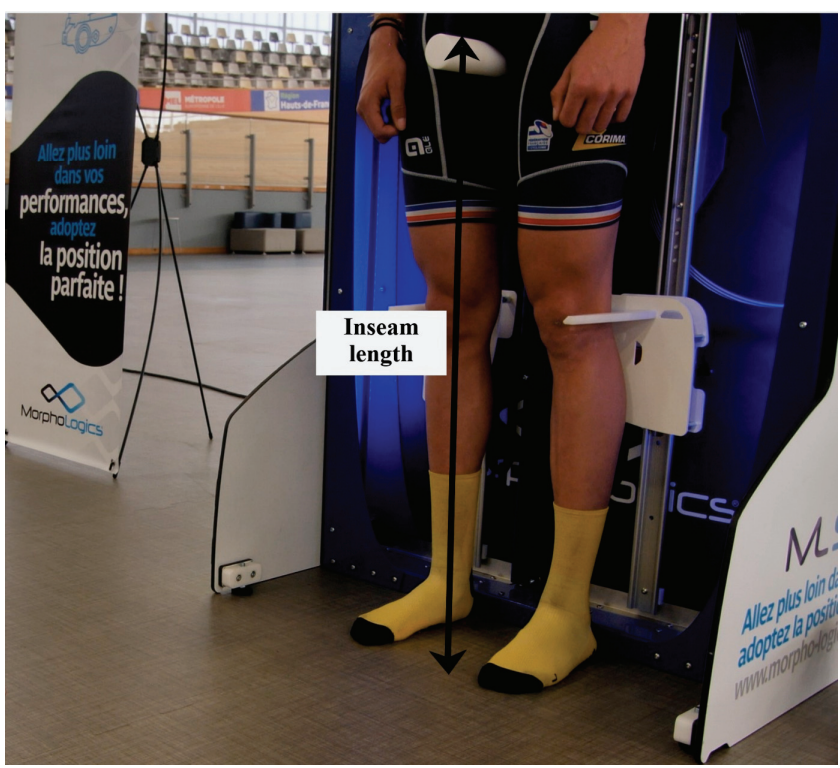

Fig. 1. Inseam length measurement with the ML Size ${ }^{\circledR}$

\section{Procedures}

The bike of each cyclist was mounted on a Cyclus $2^{\mathbb{R}}$ electromagnetic brake ergometer (RBM elektronik-auto- mation $\mathrm{GmbH}$, Leipzig, Germany) enabling the control of crank power output and pedalling cadence. The participants pedalled at $100 \mathrm{~W}$ and $80 \mathrm{rpm}$ for a duration of 3 minutes. Power output and pedalling cadence were kept constant throughout the pedalling exercise to reduce the influence of these parameters on the sagittal plane joint angles [2]-[22]. Joint kinematics was measured at $60 \mathrm{~Hz}$ during 5 seconds prior to pedalling exercise in static position with pedal at BDC and for 15 consecutive crank cycles during the last minute of the pedalling exercise by a high-resolution digital camera (Go Pro Hero $3^{\circledR}$, San Mateo, California, USA, $1280 \times 1080$ pixels of resolution) which was positioned at $4 \mathrm{~m}$ and perpendicular to the cyclist [11]. Reflective markers were prior placed on the greater trochanter, lateral femoral epicondyle, lateral malleolus, and fifth metatarsal head of the left lower limb by the same experimenter for all cyclists to reduce inter-experimenter variability [23]. Kinematic data were extracted and analysed with kinematics analysis software (Kinovea V0.8.24, Kinovea open source project, www.kinovea.org). A correction of parallax and a correction of distortion were made using this software. KA, HA (angle between the thigh and the vertical) and AA (angle between the leg and the foot; $0^{\circ}$ corresponds to full ankle extension) were measured when the pedal was at BDC in static condition and during pedalling (Fig. 2A), as well as while maximum knee extension during pedalling (Fig. 2B).

\section{Statistical analysis}

Data are reported in table 1 as mean $\pm \mathrm{SD}$ and $95 \%$ confidence intervals of mean difference $(95 \% \mathrm{CI})$.
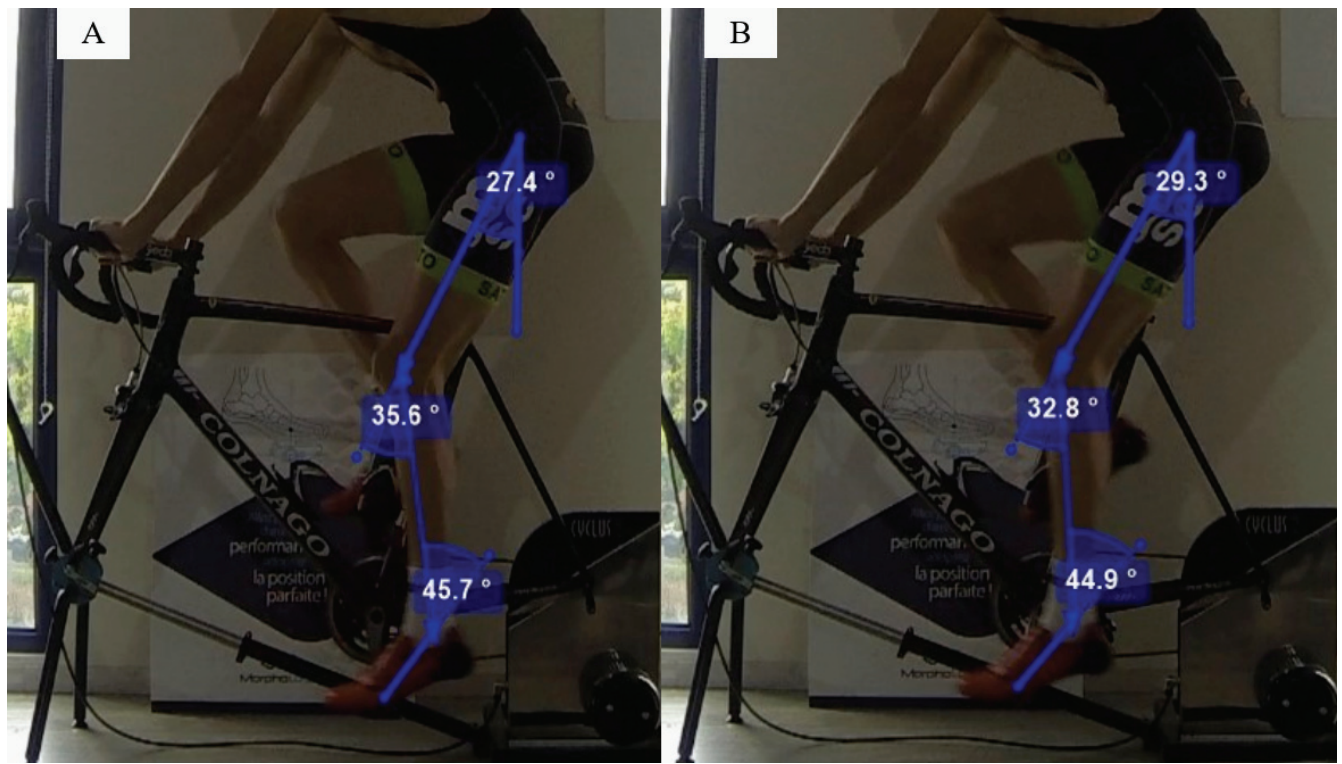

Fig. 2. Typical values of hip angle (HA), knee angle (KA) and ankle angle (AA) measured while pedalling with optimal saddle height (assessed by the Millour method) when the pedal was at BDC (A) and during maximal knee extension (B) $\left(\mathrm{GoPro}^{\mathbb{B}}\right.$ images displayed in Kinovea ${ }^{\mathbb{B}}$ software) 
Statistical analysis was carried out using Past Software (PAlaeontological STatistics, Oslo, Norway). Normality of distribution and homogeneity of the variances were tested using Shapiro-Wilk and Levene tests, respectively. A one-way ANOVA with repeated measures, or Friedman non-parametric statistical tests, in the case of non-homogeneity of the variances or non-normality of the distribution, were used to compare the means of KA, AA and HA with the three measurement methods for the total population, the group of children (IL $<0.80 \mathrm{~m}$ ) and the group of adults (IL $>0.80 \mathrm{~m}$ ). Fisher's LSD tests, as post-hoc tests for ANOVA, or pairwise Wilcoxon tests, as post-hoc tests for Friedman tests, were used to establish statistical differences between the measurement conditions. The significance level was established to $p<0.05$ for all statistical tests. Effect sizes (ES) were computed by the ratio of mean to standard deviation in score differences when significant differences were found.

\section{Results}

In Table 1, KA, HA, and AA values measured for all participants, the children and the adults in the three measurement conditions are shown.

For the total population, KA measured during Static BDC was respectively by 8 and $5^{\circ}$ lower than KA measured while Dynamic BDC (ES $=1.1,95 \%$ CI $\left.\left[5.6,12.0^{\circ}\right]\right)$ and while Dynamic MKE $(\mathrm{ES}=0.7$, $95 \%$ CI $\left.\left[2.5,9.0^{\circ}\right]\right)$. Dynamic BDC increased significantly KA by $3^{\circ}$, compared to Dynamic MKE $\left(\mathrm{ES}=2.5,95 \%\right.$ CI $\left.\left[2.6,3.5^{\circ}\right]\right)$. Significant differences were also observed for hip and ankle kinematics. HA measured during Static BDC was by $5^{\circ}$ lower than Dynamic BDC (ES $=1.2,95 \%$ CI $\left.\left[3.3,6.7^{\circ}\right]\right)$ and by $7^{\circ}$ lower than Dynamic MKE (ES $=1.5,95 \%$ CI $\left.\left[4.9,8.4^{\circ}\right]\right)$. HA measured while Dynamic MKE was by $2^{\circ}$ greater than Dynamic BDC $(\mathrm{ES}=2.1,95 \% \mathrm{CI}$ $\left.\left[1.4,2.0^{\circ}\right]\right)$. AA measured during Static BDC was by $7^{\circ}$ higher than Dynamic BDC (ES $=1.2,95 \%$ CI $\left.\left[4.2,8.3^{\circ}\right]\right)$ and by $7^{\circ}$ higher than Dynamic MKE $\left(\mathrm{ES}=1.2,95 \%\right.$ CI $\left.\left[4.6,8.9^{\circ}\right]\right)$. However, AA while Dynamic BDC was equivalent to measurements during Dynamic MKE.

For children (IL $<0.80 \mathrm{~m}$ ), KA measured while Static BDC was respectively inferior by 12 and $9^{\circ}$ compared to Dynamic BDC (ES $=1.2,95 \%$ CI $\left.\left[8.3,16.5^{\circ}\right]\right)$ and Dynamic MKE (ES $=0.9,95 \%$ CI $\left.\left[5.6,13.9^{\circ}\right]\right)$. Thus, difference between the two dynamic conditions was $3^{\circ}\left(\mathrm{ES}=3.6,95 \% \mathrm{CI}\left[2.4,3^{\circ}\right]\right)$. In regards to hip kinematics, HA measured during Static BDC was by 6 and $8^{\circ}$ lower than during Dynamic BDC (ES $=1.1$, $95 \%$ CI $\left.\left[4.3,8.7^{\circ}\right]\right)$ and Dynamic MKE (ES $=1.4$, $95 \%$ CI $\left.\left[6.0,10.8^{\circ}\right]\right)$, respectively, while the difference between Dynamic BDC and Dynamic MKE was $2^{\circ}$ $\left(\mathrm{ES}=2.2,95 \% \mathrm{CI}\left[1.6,2.3^{\circ}\right]\right)$. With respect to ankle kinematics, Static BDC increased AA by $6^{\circ}$ compared to Dynamic BDC ( $\left.\mathrm{ES}=1.0,95 \% \mathrm{CI}\left[4.1,9.3^{\circ}\right]\right)$ and Dynamic MKE (ES $=1.1,95 \%$ CI $\left.\left[4.1,8.7^{\circ}\right]\right)$, respectively, and no significant difference was detected between the two dynamic conditions.

For adults (IL $>0.80 \mathrm{~m}$ ), Static BDC decreased KA by 7 and $4^{\circ}$ compared to Dynamic BDC (ES = $1.2,95 \%$ CI $\left.\left[4.8,9.6^{\circ}\right]\right)$ and Dynamic MKE (ES = $0.6,95 \%$ CI $\left.\left[1.6,6.4^{\circ}\right]\right)$. Thereby, KA was by $3^{\circ}$ superior during Dynamic BDC compared to Dynamic MKE $\left(\mathrm{ES}=2.6,95 \%\right.$ CI $\left.\left[2.8,3.8^{\circ}\right]\right)$. During Static BDC, HA was respectively by 4 and by $5^{\circ}$ lower than during Dynamic BDC (ES $=1.0,95 \%$ CI $\left.\left[3.1,6.6^{\circ}\right]\right)$ and Dynamic MKE (ES $=1.3,95 \%$ CI $\left[4.3,7.8^{\circ}\right]$ ). The difference between Static BDC and dynamic MKE was $1^{\circ}\left(\mathrm{ES}=2.1,95 \%\right.$ CI $\left.\left[1.0,1.5^{\circ}\right]\right)$. Regarding ankle kinematics, AA measured while Static BDC was by 8 and $9^{\circ}$ greater than AA measured while Dynamic BDC $\left(\mathrm{ES}=1.3,95 \% \mathrm{CI}\left[5.0,9.2^{\circ}\right]\right)$ and Dynamic MKE (ES $=1.2,95 \%$ CI $\left.\left[5.3,10.3^{\circ}\right]\right)$, respectively. Statistical analysis showed no significant difference between AA measured during Dynamic BDC and Dynamic MKE.

Table 1. Comparison of knee angles (KA), hip angles (HA) and ankle angles (AA) in the three measurement conditions (Static BDC, Dynamic BDC, Dynamic MKE) for the total population, the children and the adults. Data are reported as means $\pm \mathrm{SD} ; *$ Significantly different of Static BDC $(p<0.05)$; + Significantly different of Dynamic MKE $(p<0.05)$

\begin{tabular}{|l|c|c|c|c|c|c|c|c|c|}
\hline & \multicolumn{3}{|c|}{ Total population $(n=26)$} & \multicolumn{2}{c|}{ Children $(\mathrm{IL}<0.80 \mathrm{~m})(n=8)$} & \multicolumn{2}{c|}{ Adults $(\mathrm{IL}>0.80 \mathrm{~m})(n=18)$} \\
\hline & $\begin{array}{c}\text { Static BDC } \\
(\text { degrees })\end{array}$ & $\begin{array}{c}\text { Dynamic } \\
\text { MKE } \\
(\text { degrees })\end{array}$ & $\begin{array}{c}\text { Dynamic } \\
\text { BDC } \\
(\text { degrees })\end{array}$ & $\begin{array}{c}\text { Static } \\
\text { BDC } \\
(\text { degrees })\end{array}$ & $\begin{array}{c}\text { Dynamic } \\
\text { MKE } \\
(\text { degrees })\end{array}$ & $\begin{array}{c}\text { Dynamic } \\
\text { BDC } \\
(\text { degrees })\end{array}$ & $\begin{array}{c}\text { Static } \\
\text { BDC } \\
(\text { degrees })\end{array}$ & $\begin{array}{c}\text { Dynamic } \\
\text { MKE } \\
(\text { degrees })\end{array}$ & $\begin{array}{c}\text { Dynamic } \\
\text { BDC } \\
(\text { degrees })\end{array}$ \\
\hline KA & $30 \pm 9$ & $35 \pm 5^{*}$ & $38 \pm 5^{+}$ & $28 \pm 9$ & $37 \pm 6^{*}$ & $40 \pm 6^{*+}$ & $31 \pm 9$ & $35 \pm 4^{*}$ & $38 \pm 4^{*^{+}}$ \\
\hline HA & $22 \pm 6$ & $29 \pm 3^{*}$ & $27 \pm 3^{+}$ & $21 \pm 6$ & $29 \pm 4^{*}$ & $27 \pm 3^{*}$ & $23 \pm 6$ & $28 \pm 3^{*}$ & $27 \pm 3^{*^{+}}$ \\
\hline AA & $57 \pm 7$ & $50 \pm 6^{*}$ & $50 \pm 7^{*}$ & $53 \pm 9$ & $47 \pm 8^{*}$ & $47 \pm 9^{*}$ & $58 \pm 6$ & $49 \pm 4^{+}$ & $50 \pm 5^{*}$ \\
\hline
\end{tabular}




\section{Discussion}

The purpose of the study was to compare lower limb joint angles 1) in static with pedal at BDC, 2) in dynamics (while pedalling) with pedal at BDC, and 3) during maximum knee extension. Our results suggest an influence of the measurement condition on HA, KA, and AA.

We found a significant difference of around $8^{\circ}$ between static and dynamic KA with pedal at BDC for the total population. This result is in the range with those reported in previous studies [6], [8], [11], [22], i.e., between 5 to $10^{\circ}$. Therefore, we can suggest a new range of $33-43^{\circ}$ for KA during Dynamic BDC by adding $8^{\circ}$ to the optimal range of $25-35^{\circ}$ without pedalling [16]. However, we observed that the variation in KA measurement between Static BDC and Dynamic BDC was different for the two groups of cyclists. In fact, children had a difference of $12^{\circ}$ while adults presented a difference of $7^{\circ}$ between the two conditions. The alterations of KA between static and dynamic conditions would be related to the larger HA and the smaller AA during pedalling. Thus, the transition from static position to active pedalling would affect joint angles [6], and particularly foot positioning [15]-[22]. Authors reported that these alterations would be required in dynamics to maintain a KA allowing for an effective pedalling [6]-[22]. The hip and knee joint extensors may be longer and the ankle plantar flexors may be shorter while pedalling, which may affect the muscle tendon unit length and the force production. Differences in joint angles might be caused by the lack of angular momentum in static, as opposed to dynamics [6]. Moreover, it has been demonstrated that cyclists can improve pedalling technique by increasing pedal force effectiveness. To do this, they have to apply pedal forces perpendicular to the cranks in the direction of crank motion [5]. However, Kautz et al. [18] observed that changing the foot orientation during the pedalling cycle could modify the orientation of the forces on the pedals. Consequently, we can suggest that riders used greater plantarflexion in dynamic conditions to improve pedal force effectiveness. In addition, the large difference between KA measured during Static BDC and Dynamic BDC in the child population could be related to the difficulty of adopting lower limb kinematics similar to that used during the pedalling movement due to their poor cycling experience, as reported by Millour et al. [19]. Therefore, dynamic measurement seems more ecological by being representative of usual practice condition [10], [11].

KA during dynamic MKE was by $3^{\circ}$ lower than the value measured during dynamic BDC. This con- firms that the range of $33-43^{\circ}$ during Dynamic BDC (i.e., $3^{\circ}$ greater than the optimal range of $30-40^{\circ}$ during dynamic MKE [10]) can be considered as an alternative for the saddle height adjustment optimisation based on knee kinematics, especially since the difference is similar regardless of the age and morphology of cyclists. It has been demonstrated that the seat tube angle (i.e., angle between the seat tube and the horizontal) does not impact KA during Dynamic MKE [23]. However, we can assume that a lower seat tube angle implies a flexed knee at BDC, which could explain the difference between the two dynamic conditions. In the study all cyclists used their own bike with a seat tube angle between $72^{\circ}$ and $75^{\circ}$ and a saddle fore-aft position adjusted respecting the method of Silberman [27]. However, seat tube angle in triathlon is between 78 and $82^{\circ}$ [23]. Therefore, we can suggest that precautions should be taken with the knee angle measurement at BDC for this discipline.

However, not taking KA measured during upright posture (which varies for each individual) as a knee offset value during cycling into account appears as a limitation [24]. Moreover, it is relevant to note that mountain bikers use generally a more upright posture than road bikers that can affect trunk angle [1] and, therefore, pelvis anteversion. However, HA was considered as the angle between the thigh and the vertical in order to take only the lower limb kinematics into account and to avoid that trunk angle impacts this variable during the analysis. In addition, AA and KA during pedalling would be dependant of the intensity due to the application of higher propulsive torque in relation to the power requirement [22]. In the current study, the power output was lower than in previous studies related to saddle height adjustment based on knee kinematics [9], [20], [21] to take into account the differences of level between the participants and especially between the children of around 10 years old and the adults. Thus, the power output of $100 \mathrm{~W}$ has allowed all cyclists to be in submaximal condition in order to avoid any changes in KA and AA kinematics that can appear at high intensity [22]. The cadence of $80 \mathrm{rpm}$ was also slightly lower than in previous studies, which generally used cadence between 90 and 100 rpm [9], [10], [21], to improve the accuracy of video analysis. Given that authors showed no differences in $\mathrm{HA}, \mathrm{KA}$ and AA between cadence of $73 \pm 7 \mathrm{rpm}$ and cadence of $90 \pm 11 \mathrm{rpm}$ [2], we could consider that this parameter did not influence the kinematic results. Therefore, this study provides original findings illustrating the relation between the saddle height adjustment methodology choices and the cycling biomechanics optimisation. 


\section{Conclusions}

In conclusion, different methods based on KA can be employed for the saddle height adjustment (Static vs. Dynamics or BDC vs. MKE). However, each methodology needs to adapt the optimal KA range. The ranges of $25-35^{\circ}$ during Static BDC and $30-40^{\circ}$ while Dynamic MKE produce identical saddle height. Moreover, we can suggest a KA range of $33-43^{\circ}$ for Dynamic BDC in road and mountain bike. The KA difference of $3^{\circ}$ between the two dynamic conditions could be caused by the seat tube angle at BDC and, therefore, it seems important to take precautions in triathlon with larger seat tube angle during the Static BDC and Dynamic BDC measurements. HA and AA modifications, according to the method used, suggest that dynamic saddle height adjustments would be more representative of usual practice conditions, especially since cycling experience seems necessary to choose a joint kinematics in static close to the pedalling movement. These recommendations could help cyclists, coaches, researchers, and clinicians to improve cycling biomechanics which is determinant for both health and performance.

\section{Acknowledgements}

The authors thank the Morphologics Company, particularly Michel Le Goallec and William Le Goallec, for their involvement in this study. In addition, the authors thank Frederyck Dutent and Martin Bouedo for their help in writing the article in English.

\section{References}

[1] Bertucci W.M., Rogier S., Reiser R.F., Evaluation of aerodynamic and rolling resistances in mountain-bike field conditions, J. Sports Sci., 2013, 31 (14), 1606-1613, DOI: https://doi.org/ 10.1080/02640414.2013.792945.

[2] Bini R.R., Rossato M., Diefenthaele F., Carpes F.P., Pedaling cadence effects on joint mechanical work during cycling, Isokinet. Exerc. Sci., 2010, 18 (1), 7-13, DOI: 10.3233/ IES-2010-0361.

[3] Bini R.R., TAMBorindeguy A.C., MotA C.B., Effects of saddle height, pedaling cadence, and workload on joint kinetics and kinematics during cycling, J. Sport Rehab., 2010, 19 (3), 301-314, DOI: https://doi.org/10.1123/jsr.19.3.301.

[4] Bini R.R., Hume P.A., CROFT J.L., Effects of bicycle saddle height on knee injury risk and cycling performance, Sports Med., 2011, 41 (6), 463-476, DOI: https://doi.org/10.2165/ 11588740-000000000-00000.

[5] Bini R.R., Hume P.A., Croft J.L., Kilding A., Pedal force effectiveness in Cycling: a review of constraints and training effects, J. Sci. Cycling, 2013, 2 (1), 11-24.
[6] Bini R.R., Hume P.A., A comparison of static and dynamic measures of lower limb joint angles in cycling: application to bicycle fitting, Hum. Mov., 2016, 17 (1), 36-42, DOI: 10.1515/ humo-2016-0005.

[7] De Vey Mestdagh K., Personal perspective: in search of an optimum cycling posture, Appl. Ergon., 1998, 29 (5), 325-334, DOI: https://doi.org/10.1016/S0003-6870(97)00080-X.

[8] Farrell K.C., Reisinger K.D., Tillman M.D., Force and repetition in cycling: possible implications for iliotibial band friction syndrome, The Knee, 2003, 10 (1), 103-109, DOI: https://doi.org/10.1016/S0968-0160(02)00090-X.

[9] Ferrer-Roca V., Bescós R., Roig A., Galilea P., Valero O., GARCÍA-LÓPEZ J., Acute effects of small changes in bicycle saddle height on gross efficiency and lower limb kinematics, J. Strength Cond. Res., 2014, 28 (3), 784-791, DOI: 10.1519/ JSC.0b013e3182a1fla9.

[10] Ferrer-Roca V., Roig A., Galilea P., Garcia-Lopez J., Influence of saddle height on lower limb kinematics in welltrained cyclists: static vs. dynamic evaluation in bike fitting, J. Strength Cond. Res., 2012, 26 (11), 3025-3029, DOI: 10.1519/JSC.0b013e318245c09d.

[11] Fonda B., SARABON N., Li F.X., Validity and reliability of different kinematics methods used for bike fitting, J. Sports Sci., 2014, 32 (10), 940-946, DOI: https://doi.org/10.1080/ 02640414.2013 .868919 .

[12] Fonda B., SARABON N., BLACKLOCK R., Li F.X., Effects of changing seat height on bike handling, J. Sci. Cycling, 2014, 3 (2), 19, DOI: 10.13140/2.1.1828.5445.

[13] GenZling C., Le dossier de la position, Géométrie d'une pléiade [Bike fitting file, Geometry of a pleiad], In Le Cycle, 1980, 53 (32), 32-36.

[14] Hamley E.Y., Thomas V., Physiological and postural factors in the calibration of the bicycle ergometer, J. Physiol., 1967, 191 (2), 55-56.

[15] Holliday W., Fisher J., Theo R., Swart J., Static versus dynamic kinematics in cyclists: A comparison of goniometer, inclinometer and $3 D$ motion capture, Eur. J. Sports Sci., 17 (9), 2017, 1129-1142, DOI: https://doi.org/10.1080/ 17461391.2017.1351580.

[16] Holmes J.C., PruitT A.L., Whalen N.J., Lower extremity overuse in bicycling, Clin. Sports Med., 1994,13 (1), 187-205.

[17] JOHNSTON T.E., Biomechanical considerations for cycling interventions in rehabilitation, Phys. Ther., 2007, 87 (9), 1243-1252, DOI: https://doi.org/10.2522/ptj.20060210.

[18] Kautz S.A., Feltner M.E., COYle E.F., Baylor A.M., The pedaling technique of elite endurance cyclists: changes with increasing workload at constant cadence, J. Appl. Biomech., 1991, 7 (1), 29-53, DOI: https://doi.org/10.1123/ijsb.7.1.29.

[19] Millour G., Duc S., Puel F., Bertucci W., Comparison of two static methods of saddle height adjustment for cyclists of different morphologies, Sports Biomech., 2019, 1-16, DOI: 10.1080/14763141.2018.1556324.

[20] Peveler W.W., Pounder J.D., Bishop P.A., Effects of saddle height on anaerobic power production in cycling, J. Strength Cond. Res., 2007, 21(4), 1023-1027, DOI: 10.1519/R-20316.1.

[21] Peveler W.W., Effects of saddle height on economy in cycling, J. Strength Cond. Res., 2008, 22(4), 1355-1359, DOI: 10.1519/JSC.0b013e318173dac6.

[22] Peveler W.W., Shew B., Johnson S., PAlmer T.G., A kinematic comparison of alterations to knee and ankle angles from resting measures to active pedaling during a graded exercise protocol, J. Strength Cond. Res., 2012, 26 (11), 3004-3009, DOI: 10.1519/JSC.0b013e318243fdcb. 
[23] PRICE D., DonNE B., Effect of variation in seat tube angle at different seat heights on submaximal cycling performance in man, J. Sports Sci., 1997, 15(4), 395-402, DOI: 10.1080/ 026404197367182.

[24] Priego Quesada J.I., Jacques T.C., Bini R.R., Carpes F.P., Importance of static adjustment of knee angle to determine saddle height in cycling, J. Sci. Cycling, 2016, 5 (1), 26-31.

[25] Priego Quesada J.I., Pérez-Soriano P., Lucas-Cuevas A.G., Salvador Palmer R., Cibrián Ortiz De ANDa R.M., Effect of bike-fit in the perception of comfort, fatigue and pain, J. Sports Sci., 2017, 35(14), 1459-1465, DOI: https://doi.org/ 10.1080/02640414.2016.1215496.
[26] Priego Quesada J.I., Kerr Z.Y., Bertucci W.M., Carpes F.P., The categorization of amateur cyclists as research participants: findings from an observational study, J. Sports Sci., 2018, 36 (17), 2018-2024, DOI: https://doi.org/10.1080/ 02640414.2018 .1432239$.

[27] Silberman M.R., Webner D., Collina S., Shiple B.J., Road bicycle fit, Clinical J. Sports Med., 2005, 15(4), 271-276, DOI: $10.1097 / 01$.jsm.0000171255.70156.da.

[28] Verma R., Hansen E.A., De Zee M., Madeleine P., Effect of seat positions on discomfort, muscle activation, pressure distribution and pedal force during cycling, J. Electromyogr. Kines., 2016, 27, 78-86, DOI: https://doi.org/10.1016/ j.jelekin.2016.02.003. 